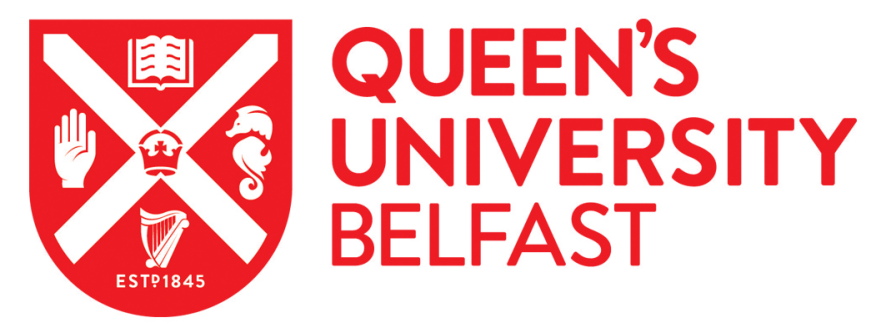

\title{
Discovery of a New Solvent Co-Catalyzed Mechanism in Heterogeneous Catalysis: A First-Principles Study with Molecular Dynamics on Acetaldehyde Hydrogenation on Birnessite
}

Xie, W., Reid, G., \& Hu, P. (2022). Discovery of a New Solvent Co-Catalyzed Mechanism in Heterogeneous Catalysis: A First-Principles Study with Molecular Dynamics on Acetaldehyde Hydrogenation on Birnessite. JACS Au. https://doi.org/10.1021/jacsau.1c00452

Published in:

JACS Au

Document Version:

Publisher's PDF, also known as Version of record

Queen's University Belfast - Research Portal:

Link to publication record in Queen's University Belfast Research Portal

\begin{abstract}
Publisher rights
Copyright 2022 the authors. Published by American Chemical Society

This is an open access article published under a Creative Commons Attribution-NonCommercial-NoDerivs License

(https://creativecommons.org/licenses/by-nc-nd/4.0/), which permits distribution and reproduction for non-commercial purposes, provided the author and source are cited.
\end{abstract}

\section{General rights}

Copyright for the publications made accessible via the Queen's University Belfast Research Portal is retained by the author(s) and / or other copyright owners and it is a condition of accessing these publications that users recognise and abide by the legal requirements associated with these rights.

Take down policy

The Research Portal is Queen's institutional repository that provides access to Queen's research output. Every effort has been made to ensure that content in the Research Portal does not infringe any person's rights, or applicable UK laws. If you discover content in the

Research Portal that you believe breaches copyright or violates any law, please contact openaccess@qub.ac.uk. 


\title{
Discovery of a New Solvent Co-Catalyzed Mechanism in Heterogeneous Catalysis: A First-Principles Study with Molecular Dynamics on Acetaldehyde Hydrogenation on Birnessite
}

\author{
Wenbo Xie, ${ }^{\dagger}$ Glenn Reid, ${ }^{\dagger}$ and P. Hu* \\ Cite This: https://doi.org/10.1021/jacsau.1c00452 \\ Read Online
}

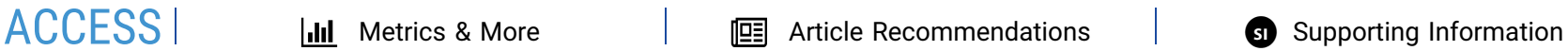

ABSTRACT: Heterogenous hydrogenation reactions are essential in a wide range of chemical industries. In this work, we find that the hydrogenation of acetaldehyde on birnessite cannot occur through the traditional mechanisms due to the strong adsorption of the aldehyde and hydrogen on the surface, using first-principles calculations. We discover that this reaction can occur feasibly via a solvent-cocatalyzed mechanism with molecular hydrogen in the liquid phase: a methanol solvent or a similar solvent is required for the reaction. Free energy calculations shows that the methanol solvent preferentially fills the oxygen vacancies of the catalyst surface and spontaneously dissociates on the surface, in which the resulting hydroxyl group then acts as the coordination site for the carbonyl bond and allows the reaction to proceed without adsorption of the reactants on the surface. The

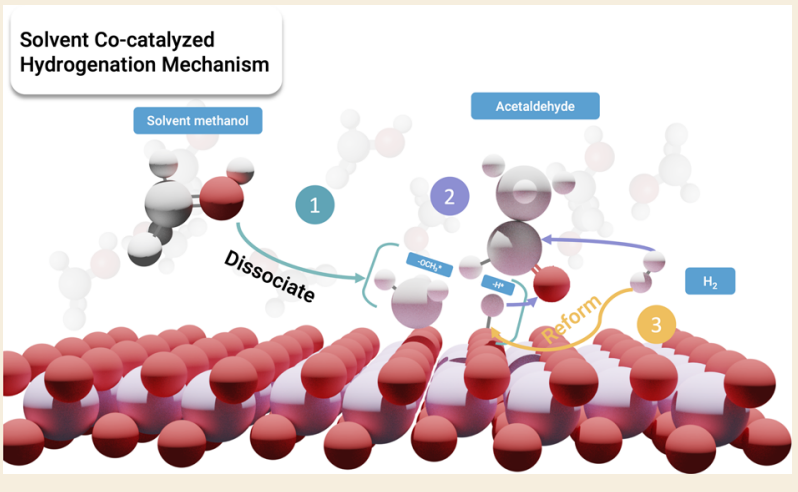
reasons this new mechanism is more favorable over the traditional mechanisms in the literature are scrutinized and discussed. The new mechanism may be followed in many other systems.

KEYWORDS: Hydrogenation, DFT, Molecular Dynamics

\begin{abstract}
TTy ydrogenation reactions in heterogeneous catalysis are among the most important reactions. In particular, the hydrogenation of aldehydes is vital in a plethora of industrial applications, which include the food, petrochemical, and fragrance industries. ${ }^{1-6}$ However, traditional mechanisms in heterogeneous catalysis become pinched in facing a wide range of catalysts and a variety of reaction environments. ${ }^{7}$ In this letter, we present a novel solvent-cocatalyzed hydrogenation mechanism that bypasses the overly strong adsorption of key reactants, using acetaldehyde hydrogenation on birnessite as an example. In the presence of methanol solvent, an alternative reaction pathway was established, and the details of this process under the solid-liquid environment were fully captured via first-principles free energy calculations using $a b$ initio molecular dynamics (AIMD) simulations.

In general, a surface reaction can proceed through one of three main mechanisms in heterogeneous catalysis: namely (i) the Langmuir-Hinshelwood mechanism (Figure 1a), ${ }^{8}$ (ii) the Eley-Rideal mechanism (Figure 1b), ${ }^{9}$ and (iii) the Mars-Van Krevelen mechanism (Figure 1c). ${ }^{10}$ For hydrogenation reactions on solid catalysts, more specific mechanisms, Horiuti-Polanyi and non-Horiuti-Polanyi mechanisms, both of which belong to Langmuir-Hinshelwood style mechanisms, were reported. The Horiuti-Polanyi mechanism is the most commonly accepted mechanism for hydrogenation reactions, as shown in Figure $1 \mathrm{~d} .{ }^{11-15}$ This mechanism is prevalent in a
\end{abstract}

wide range of hydrogenations, including the saturation of aldehydes, ketones, and alkenes. ${ }^{3,16-20}$ However, there are occasions whereby the hydrogenation reaction occurs via a non-Horiuti-Polanyi mechanism, reported first by our group, ${ }^{22}$ in which the hydrogenation reaction occurs via molecular hydrogen on the surface as opposed to dissociated hydrogen, as shown in Figure 1e. This occurs because some surfaces are too inert to effectively break the $\mathrm{H}-\mathrm{H}$ bond.

Experimental work showed that manganese oxide octahedral molecular sieves have great activity and selectivity for hydrogenation reactions of aldehydes. ${ }^{21}$ As one of them, birnessite, a two-dimensional layered structure comprised of edge-shared $\mathrm{MnO}_{6}$ octahedra with the interlayer region occupied by either/and water molecules or metal cations, ${ }^{22-24}$ often possesses numerous surface defects, usually as oxygen vacancies and edges. ${ }^{25}$ A surface oxygen vacancy site contains three open Mn atoms, offering a significant level of bonding with the $\mathrm{d}$ orbitals resulting in a strong adsorption site. This

Received: October 10, 2021 
(a) Langmuir-Hinshelwood mechanism

A

A)

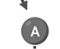

$0000 \rightarrow$

(b) Eley-Rideal mechanism
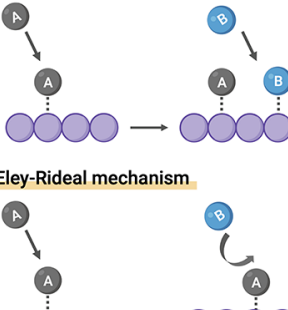

.
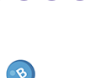

$\rightarrow$

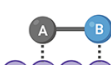

$\stackrel{A-B}{1}$
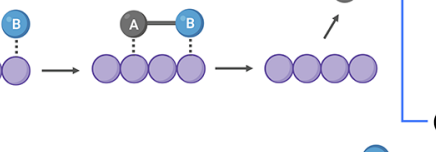

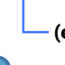

(e) Non-Horiuti-Polanyi mechanism

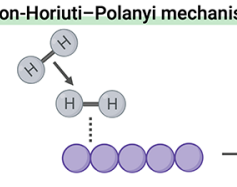

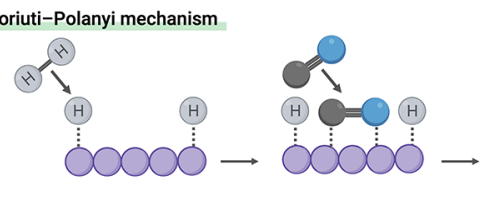

$00000^{\circ}$ H-O $\mathrm{OH}$ (H)- $-1 \mathrm{OA}^{-1}$ $00000^{\circ} \rightarrow 00000$

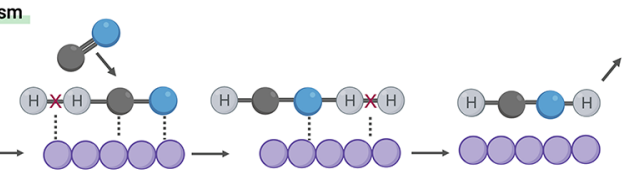

(c) Mars-Van Krevelen mechanism

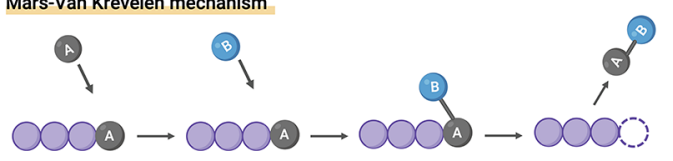

Figure 1. Schematic illustration of the three main surface mechanisms: (a) Langmuir-Hinshelwood; (b) Eley-Rideal; (c) Mars-Van Krevelen mechanism. All of the reported heterogeneous hydrogenation reactions follow Langmuir-Hinshelwood style mechanisms: (d) Horiuti-Polanyi mechanism; (e) non-Horiuti-Polanyi mechanism with molecular hydrogen.

(a)

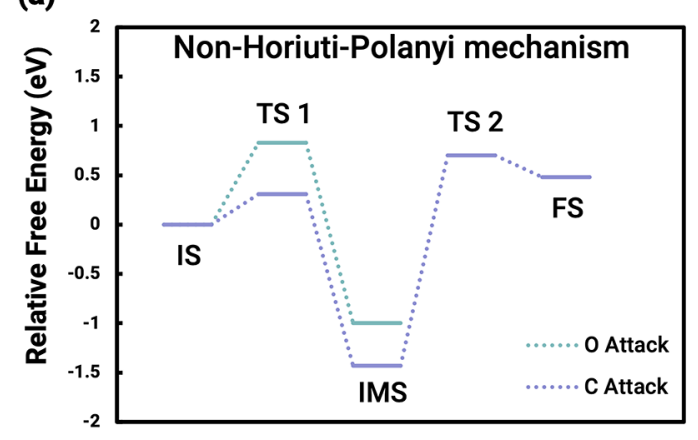

(c)

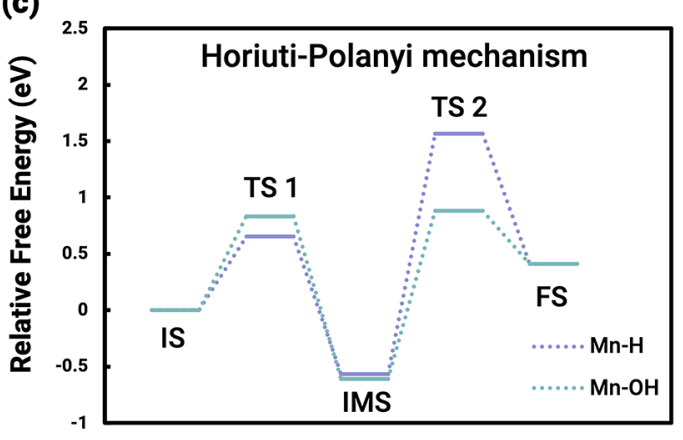

(e)

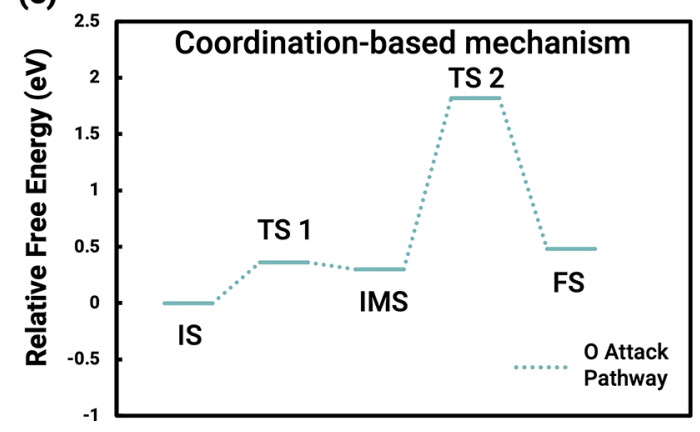

(b)

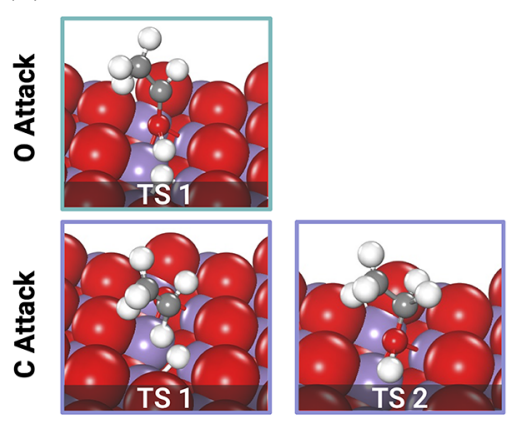

(d)
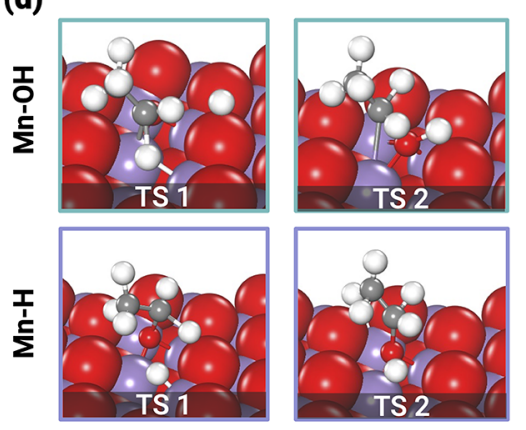

(f)

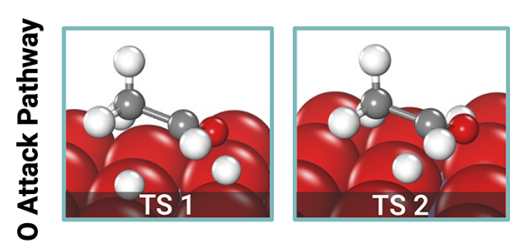

Figure 2. (a) Relative free energy profiles and (b) transition state structures from the non-Horiuti-Polanyi mechanism investigation. (c) Relative free energy profiles and (d) transition state structures from the Horiuti-Polanyi mechanism investigation. (e) Relative free energy profile and (f) transition state structures of the coordination-based hydrogenation of acetaldehyde from surface hydroxyl groups. IS, IMS, TS, and FS stand for the initial, intermediate, transition, and final states, respectively. 
leads to a fatal problem: the overly strong adsorption could hinder the reaction via the traditional ways. When it is considered that (i) the traditional mechanisms have beenextensively investigated on metal surfaces while metal oxides (common catalysts) have been less studied and (ii) all of the traditional mechanisms involve adsorption of reactants on the surface, and strong adsorption may result in very different chemistry on oxides, it is worth asking the following questions. (i) Is the Langmuir-Hinshelwood mechanism universal for all hydrogenation reactions? (ii) If not, is there an alternative mechanism? How does it allow hydrogenation reactions to proceed without the adsorption of the reactants? This speculation has stimulated our interest in exploring a fundamentally different mechanism for hydrogenation reactions.

Herein, the traditional mechanisms have been investigated using DFT and compared to the solvent-cocatalyzed mechanism resulting from exhaustive AIMD simulations in the current work. Our calculations show that, among them, the solvent-cocatalyzed mechanism is much preferred over the traditional mechanisms. The presence of methanol solvent offers multiple distinct effects that resolve the issues of overly binding reactants and significantly reduce the reaction barrier.

Without an oxygen vacancy, no adsorption of hydrogen or acetaldehyde can occur, even on the edge sites of birnessite (see Figure S2 and Table S1). When the oxygen vacancies are present, the hydrogen molecule has an adsorption energy of $-0.67 \mathrm{eV}$, and the acetaldehyde molecule possesses an adsorption energy of $-2.22 \mathrm{eV}$. The initial structure is shown in Figure S3. The Langmuir-Hinshelwood style mechanisms are first investigated. For the non-HoriutiPolanyi mechanism, the reaction can occur right after adsorption. The first step is to determine the first hydronation target in the unsaturated $\mathrm{C}=\mathrm{O}$. Our results in Figure 2a show unequivocally that the attack of the $\mathrm{C}$ is heavily favored. The barrier for attacking $\mathrm{C}$ is $0.31 \mathrm{eV}$ in comparison to $0.83 \mathrm{eV}$ for $\mathrm{O}$, which is expected as the carbon is activated from the adsorption of the $\mathrm{O}$ to the surface. The barrier for adding the second $\mathrm{H}$ to the $\mathrm{O}$ atom is substantial with a value of $2.13 \mathrm{eV}$, which makes it very hard for the reaction to proceed via the non-Horiuti-Polanyi mechanism. For the Horiuti-Polanyi mechanism, an additional step of the $\mathrm{H}_{2}$ dissociation was calculated, shown in Figure S6. Since the attack of the $\mathrm{C}$ of $\mathrm{C}=\mathrm{O}$ is heavily favored, the dissociation of $\mathrm{H}_{2}$ into $\mathrm{Mn}-\mathrm{H}$ and $\mathrm{Mn}-\mathrm{OH}$ leaves only two possible reaction pathways for the reaction to proceed. The transition states are shown in Figure $2 c$, and the reaction energy profiles are depicted in Figure $2 \mathrm{~d}$, in which $\mathrm{Mn}-\mathrm{H}$ is determined to be the favorable pathway. However, we see that these two mechanisms stumbled upon the same problem: the oxygen of acetaldehyde bonds to three $\mathrm{Mn}$ atoms, which offers a significant level of bonding with the $\mathrm{d}$ orbitals of the metal atoms, resulting in a strong bond. The overly strong adsorption of the acetaldehyde prohibits the hydrogenation of the $\mathrm{O}$ of $\mathrm{C}=\mathrm{O}$. To find a feasible pathway, an Eley-Rideal style coordination-based mechanism that avoids the binding of acetaldehyde to the surface was tested to see if this has a reducing effect on the hydrogenation barriers. The reaction mechanism and profiles are shown in Figure 2e,f. Two pathways were considered; the first one starts with hydrogenation of the $\mathrm{O}$ of $\mathrm{C}=\mathrm{O}$, and the other starts with the $\mathrm{C}$. An interesting result was observed in a search for the transition state structures of the $\mathrm{C}$ hydrogenation in the second pathway: when $\mathrm{H}$ attacks the $\mathrm{C}$, the $\mathrm{O}$ will pick the $\mathrm{H}$ first before the transition state is reached. Both pathways lead to the same mechanism with an effective barrier of $1.52 \mathrm{eV}$. This can be attributed to the low reaction barrier of the hydrogenation of the $\mathrm{O}$, and once the $\mathrm{C}=\mathrm{O}$ become less unsaturated, it can pick up the $\mathrm{H}$ instantly. However, the effective barrier is still high, and alternative approaches are needed, where both the hydrogen and acetaldehyde are not strongly adsorbed to the surface (calculation details are given in the Supporting Information).

To this end, after all the traditional mechanisms were ruled out, we tried a completely new mechanism to resolve the issues of the adsorption of hydrogen by considering the solvent in the system in the calculations. ${ }^{26-29}$ Methanol was chosen as the solvent, as it was experimentally used on similar manganese oxides in the literature. ${ }^{23,30}$ The solvent adds another competitor that can adsorb and dissociate on the surface oxygen vacancies. The free energies of adsorption of each species on an oxygen vacancy are shown in Table 1.

Table 1. Free Energies of Adsorption of Hydrogen, Acetaldehyde, and Methanol on an Oxygen Vacancy on the Birnessite Surface

\begin{tabular}{lc}
\hline \multicolumn{1}{c}{ species } & free energy of adsorption $(\mathrm{eV})$ \\
hydrogen & -0.026 \\
acetaldehyde & -1.85 \\
methanol & -2.57 \\
\hline
\end{tabular}

The free energies of adsorption show that methanol is most thermodynamically favored to adsorb on an oxygen vacancy. MD simulations were conducted to further test the results (details are given in the Supporting Information). An interesting result from the $\mathrm{MD}$ simulations was that, apart from adsorbing to the oxygen vacancy, the methanol molecule spontaneously dissociated on the surface, resulting in an $-\mathrm{OCH}_{3}$ group that fills the oxygen vacancy and $-\mathrm{H}$ on the existing surface $\mathrm{O}$ to form a hydroxy group. The hydroxyl group provides a coordination site for the carbonyl group of the aldehyde. On the basis of the MD simulations and free energy results, a dissociated methanol on the oxygen vacancy in the presence of another methanol as solvent was chosen to further investigate the hydrogenation mechanism, shown in Figure $3 a$ and Figure S8.

From the MD simulations, the hydrogen molecule is observed to reside close to the surface and parallel to the $\mathrm{C}=\mathrm{O}$ bond of the aldehyde. AIMD including explicit solvent molecules on the solid surface was used for an accurate description of the processes associated with the solid-liquid environment. $^{31-36,37}$ The free energy barriers of $\mathrm{H}_{2}$ attacking the $\mathrm{C} / \mathrm{O}$ from $\mathrm{C}=\mathrm{O}$ were then obtained using the umbrella sampling calculations within the framework of DFT (details are given in the Supporting Information), and energy profiles are shown in Figure $3 \mathrm{c}$,d. The results show that the preferred pathway is to attack the $\mathrm{C}$ of $\mathrm{C}=\mathrm{O}$ with a barrier of $0.92 \mathrm{eV}$, while the $\mathrm{O}$ attack pathway has a much greater barrier of 1.29 $\mathrm{eV}$. When the hydrogen molecule is forced to attack the carbon and the $\mathrm{C}-\mathrm{H}$ bond begins to form, the $\mathrm{O}$ of the $\mathrm{CO}$ bond simultaneously picks up the $\mathrm{H}$ of the $\mathrm{OH}$ on the surface. The other $\mathrm{H}$ of the hydrogen molecule then moves to the surface and regenerates the $\mathrm{O}-\mathrm{H}$ on the surface. This is important, as another acetaldehyde molecule can then coordinate to this hydroxyl group and the reaction can occur again with a cycle being formed. Furthermore, an equivalent gas-phase mecha- 
(a)

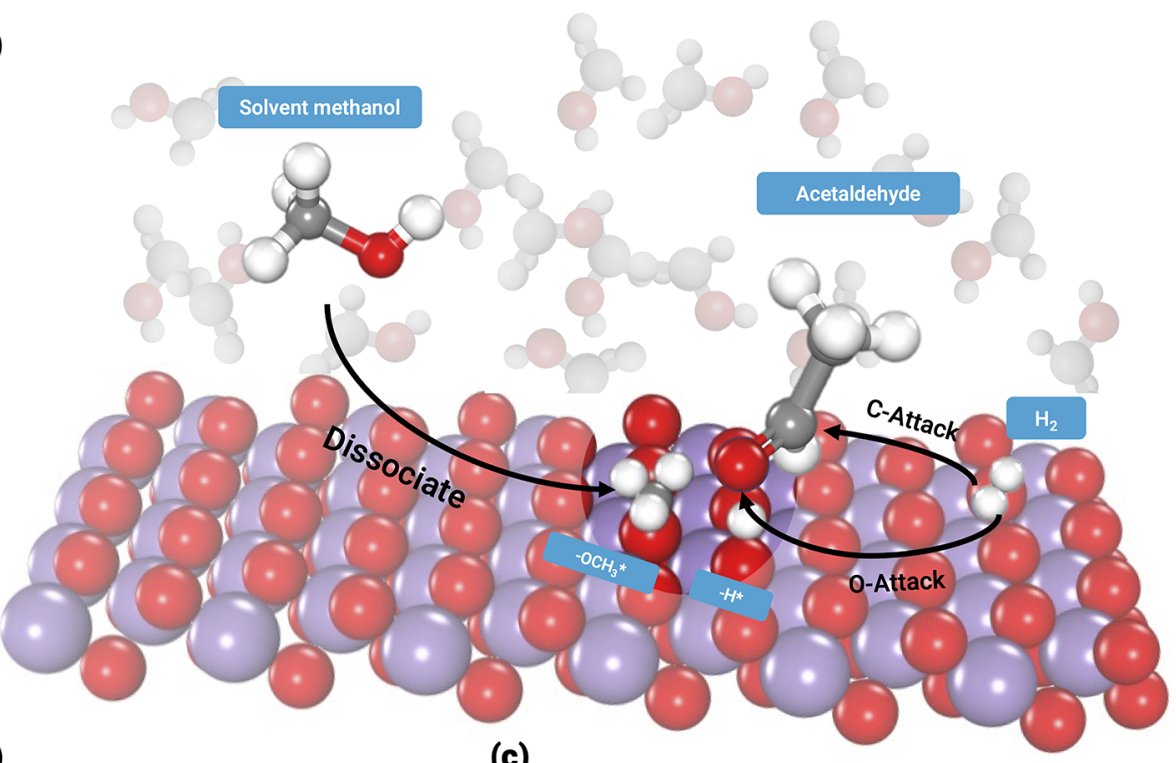

(b)

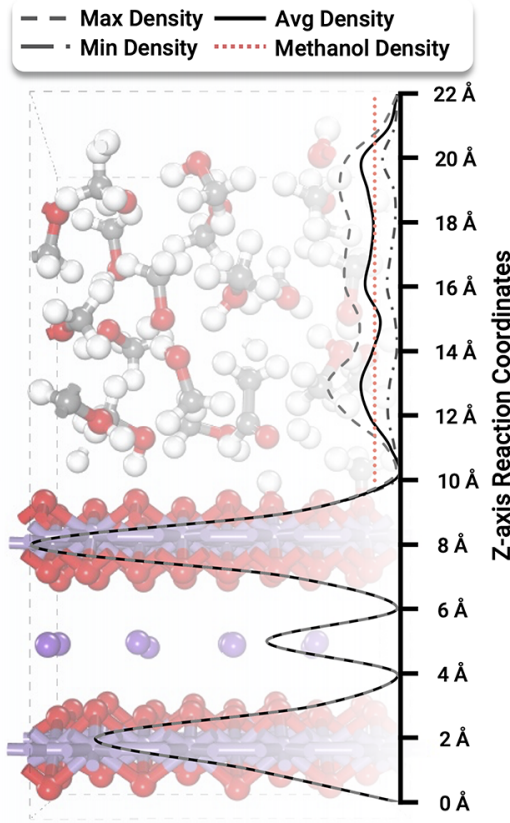

(c)
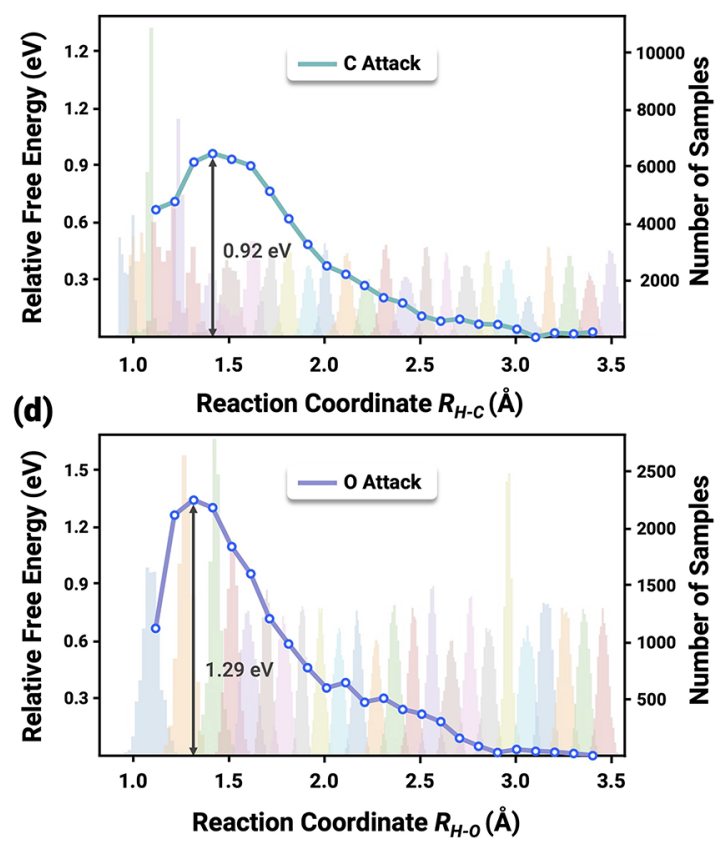

Figure 3. (a) Schematic presentation of our AIMD simulations with explicit solvent molecules. The solvent methanol adsorbs to the $\mathrm{O}$ vacancy and then dissociates into $\mathrm{OCH}_{3}$ (filling the vacancy) and $\mathrm{H}$ (on a surface $\mathrm{O}$ to form $\mathrm{OH}$ ). The two possible pathways of the first hydrogenation step are shown. (b) Atomic density profile from the AIMD simulations. The black line indicates the average atomic density, gray dashed lines indicate the minimum/maximum density flux, and the red dashed line indicates the density of standard methanol solvent $\left(792 \mathrm{~kg} / \mathrm{m}^{3}\right)$. Free energy analysis of the first hydrogenation step on birnessite in the presence of methanol solvent by umbrella sampling: (c) the $\mathrm{C}$ attack from $\mathrm{H}_{2}$ along $R_{\mathrm{H}-\mathrm{C}}$; $(\mathrm{d})$ the $\mathrm{O}$ attack from $\mathrm{H}_{2}$ along $R_{\mathrm{H}-\mathrm{O}}$. The stacked color bars are an indication of a complete sampling process, with each bar representing the number of samples collected at the reaction coordinate during the AIMD.

nism was tested against the liquid-phase mechanism for comparison using static calculations. It is found that the gasphase mechanism is not favored in comparison to the liquidphase mechanism presented in Figure 4 (see details in the Supporting Information).

A schematic presentation of the complete solventcocatalyzed mechanism with molecular hydrogen for aldehyde hydrogenation is shown in Figure 4. Unlike the water solvent in previous work which only helps to facilitate the dissociation of $\mathrm{H}_{2}{ }^{21}$ the methanol solvent provides an alternative reaction pathway. The solvent has an integral effect in not only filling the surface vacancies but also providing a hydroxyl after dissociation for coordinating acetaldehyde. The preferential solvent adsorption on the surface allows the hydrogenation reaction to occur by $\mathrm{H}_{2}$, which alleviates the high barriers observed when the hydrogen source is adsorbed on the surface. The coordination of the aldehyde to the hydroxyl group also enables the $\mathrm{O}$ of the $\mathrm{C}=\mathrm{O}$ to be hydrogenated; otherwise, the bonding of the aldehyde directly to the surface is too strong. Although the methoxy group was not involved in this reaction system, one can envisage that other specific solvents may be used to help adjust the stereochemistry of the reactants, creating a certain angle or position that facilitates specific reaction pathways. 


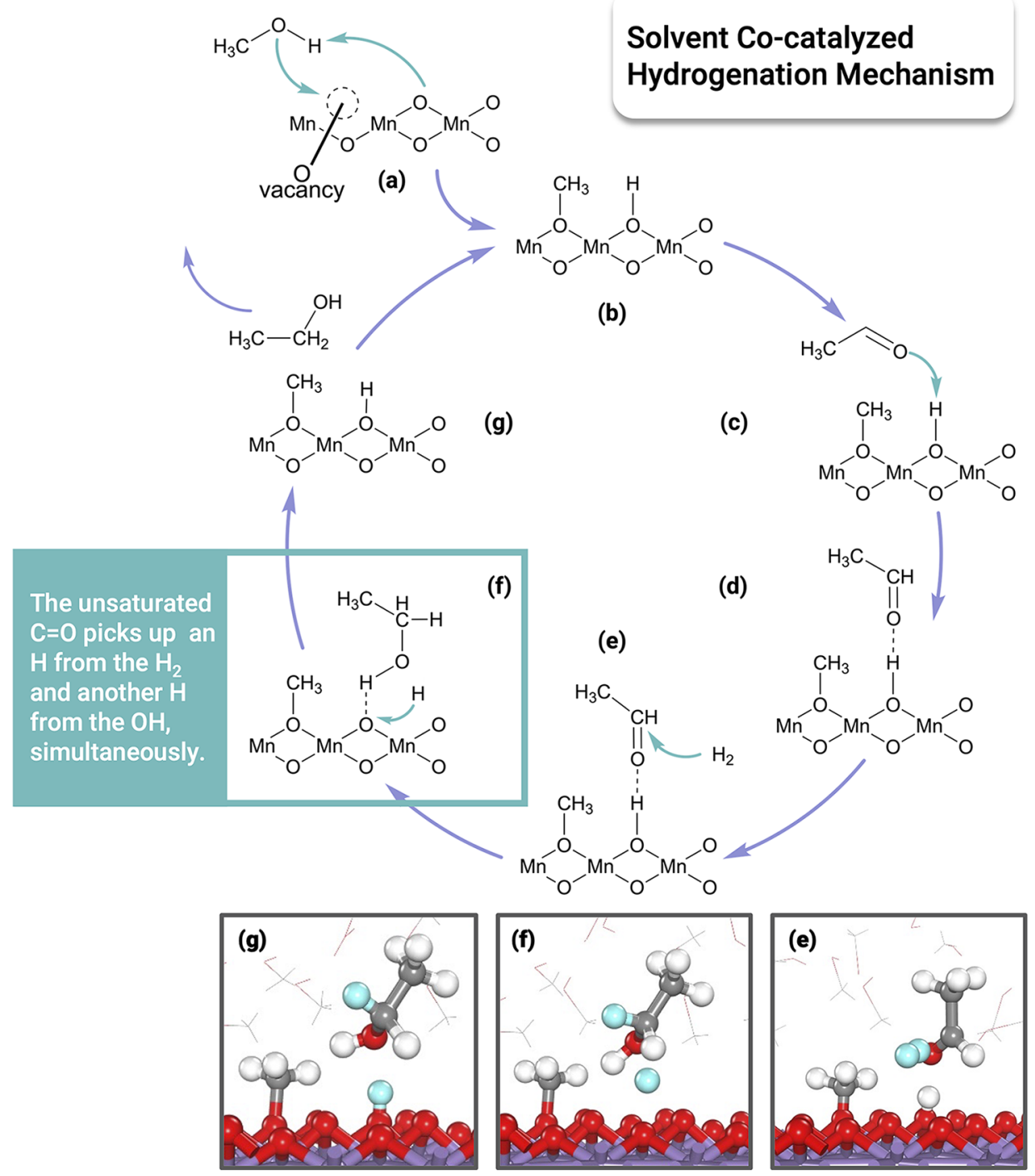

Figure 4. Reaction scheme to illustrate the new solvent-cocatalyzed mechanism in heterogeneous catalysis for the hydrogenation of acetaldehyde over birnessite in methanol solvent. Methanol acts as a cocatalyst that occupies the $\mathrm{O}$ vacancies and facilitates the coordination of acetaldehyde. The hydrogenation can occur with one $\mathrm{H}$ from molecular hydrogen and the other $\mathrm{H}$ from $\mathrm{OH}$ generated from the dissociation of the solvent. The $\mathrm{OH}$ is regenerated, and the reaction can occur again with a cycle being formed. The snapshots of MD simulations show some key reaction steps (e-g), in which the $\mathrm{H}$ atoms from $\mathrm{H}_{2}$ are highlighted in light blue.

Metal oxides are often used for hydrogenation reactions, in which the overbonding of reactants, including hydrogen, with the catalysts may be a common problem for the traditional mechanisms. Our new mechanism may overcome this problem and may be followed by many hydrogenation reactions in other systems. It is worth mentioning that the methanol solvent plays two roles here in addition to avoiding the overbonding of reactants with the surface; (i) it dissociates, yielding a hydroxyl group that can provide an anchor position for acetaldehyde to be hydrogenated near the surface where $\mathrm{H}_{2}$ is rich in concentration, and (ii) it activates the $\mathrm{CO}$ group of the acetaldehyde by coordinating it with a strong hydrogen bonding. Point ii is particularly interesting: one can envisage that a specific solvent can be designed to anchor and activate the reactants accordingly to achieve the desired selectivity. This newly established mechanism refreshes our understanding of the hydrogenation reactions in heterogeneous catalysis, and the principles revealed above may be of general use.

\section{ASSOCIATED CONTENT}

\section{Supporting Information}

The Supporting Information is available free of charge at https://pubs.acs.org/doi/10.1021/jacsau.1c00452.

Computational details for DFT calculations and AIMD simulations, energy calculations, thermodynamic corrections, and detailed investigations of the four mechanisms, including initial structures, reaction pathways, and analyses (PDF)

\section{AUTHOR INFORMATION}

\section{Corresponding Author}

P. Hu - School of Chemistry and Chemical Engineering, The Queen's University of Belfast, Belfast BT9 5AG, U.K.; (1) orcid.org/0000-0002-6318-1051; Email: p.hu@ qub.ac.uk 


\section{Authors}

Wenbo Xie - School of Chemistry and Chemical Engineering, The Queen's University of Belfast, Belfast BT9 5AG, U.K.

Glenn Reid - School of Chemistry and Chemical Engineering, The Queen's University of Belfast, Belfast BT9 5AG, U.K.

Complete contact information is available at:

https://pubs.acs.org/10.1021/jacsau.1c00452

\section{Author Contributions}

${ }^{\dagger}$ W.X. and G.L. contributed equally.

Notes

The authors declare no competing financial interest.

\section{ACKNOWLEDGMENTS}

To calculate acetaldehyde hydrogenation on birnessite was suggested by Dr. Haresh Manyar. Our simulations show that the reaction could not described by any traditional mechanisms, resulting in the discovery of a completely new mechanism. Therefore, we are very grateful for Dr. Haresh Manyar for his suggestion. W.X. also thanks Jianyan $\mathrm{Xu}$, Zhuozheng Wang, and Yulan Han for their help and fruitful discussions. NSFC (92045303) is acknowledged. We are grateful for computational support from the UK national highperformance computing service, ARCHER, for which access was obtained via the UKCP consortium and funded by EPSRC grant ref EP/P022561/1. We are grateful to the UK Materials and Molecular Modeling Hub for computational resources, which is partially funded by EPSRC (EP/P020194/1). We are grateful for access to the Queen's University Belfast Kelvin HPC service, which is partially funded by ESPRC (EP/ T022175/1).

\section{REFERENCES}

(1) Rylander, P. N. Hydrogenation and Dehydrogenation; Wiley-VCH: 2005.

(2) Bauer, K.; Garbe, D. Common Fragrance and Flavor Materials; VCH: Weinheim, 1985.

(3) Xie, W.; Xu, J.; Ding, Y.; Hu, P. Quantitative Studies of the Key Aspects in Selective Acetylene Hydrogenation on $\operatorname{Pd}(111)$ by Microkinetic Modeling with Coverage Effects and Molecular Dynamics. ACS Catal. 2021, 11 (111), 4094-4106.

(4) Yang, B.; Burch, R.; Hardacre, C.; Headdock, G.; Hu, P. Origin of the Increase of Activity and Selectivity of Nickel Doped by Au, Ag, and $\mathrm{Cu}$ for Acetylene Hydrogenation. ACS Catal. 2012, 2 (6), 10271032.

(5) Studt, F.; Abild-Pedersen, F.; Bligaard, T.; Sorensen, R. Z.; Christensen, C. H.; Norskov, J. K. Identification of Non-Precious Metal Alloy Catalysts for Selective Hydrogenation of Acetylene. Science (80-.) 2008, 320 (5881), 1320-1322.

(6) Studt, F.; Abild-Pedersen, F.; Bligaard, T.; Sørensen, R. Z.; Christensen, C. H.; Nørskov, J. K. On the Role of Surface Modifications of Palladium Catalysts in the Selective Hydrogenation of Acetylene. Angew. Chem. 2008, 120 (48), 9439-9442.

(7) Reid, G. Understanding Heterogenous Catalysis on Zeolites and Manganese Oxides; Queen's University Belfast: 2019.

(8) Langmuir, I. The Constitution and Fundamental Properties Of Solids And Liquids. Part I. Solids. J. Am. Chem. Soc. 1916, 38, 22212295.

(9) Eley, D. D.; Rideal, E. K. The Catalysis of Para-Hydrogen Conversion by Tungsten. Proc. R. Soc. Lond. A, 1941178, 429-451.

(10) Mars, P.; van Krevelen, D.W. Oxidations Carried out by Means of Vanadium Oxide Catalysts. Chem. Eng. Sci. 1954, 3, 41-59.

(11) Horiuti, I.; Polanyi, M. Exchange Reactions of Hydrogen on Metallic Catalysts. Trans. Faraday Soc. 1934, 30, 1164.
(12) Horiuti, J.; Polanyi, M. A Catalysed Reaction of Hydrogen with Water. Nature 1933, 132, 819.

(13) Horiuti, J.; Polanyi, M. Catalytic Interchange of Hydrogen between Water and Ethylene and between Water and Benzene. Nature 1934, 134, 377.

(14) Zhang, L.; Shao, Z. J.; Cao, X. M.; Hu, P. Insights into Different Products of Nitrosobenzene and Nitrobenzene Hydrogenation on $\operatorname{Pd}(111)$ under Realistic Reaction Conditions. J. Phys. Chem. C 2018, 122 (35), 20337-20350.

(15) Jørgensen, M.; Grönbeck, H. Selective Acetylene Hydrogenation over Single-Atom Alloy Nanoparticles by Kinetic Monte Carlo. J. Am. Chem. Soc. 2019, 141 (21), 8541-8549.

(16) Sinha, N. K.; Neurock, M. A First Principles Analysis of the Hydrogenation of $\mathrm{C} 1 \mathrm{C} 4$ Aldehydes and Ketones over Ru(0001). J. Catal. 2012, 295, 31-44.

(17) Mattson, B.; Foster, W.; Greimann, J.; Hoette, T.; Le, N.; Mirich, A.; Wankum, S.; Cabri, A.; Reichenbacher, C.; Schwanke, E. Heterogeneous Catalysis: The Horiuti-Polanyi Mechanism and Alkene Hydrogenation. J. Chem. Educ. 2013, 90, 613-619.

(18) Xie, W.; Hu, P. Influence of Surface Defects on Activity and Selectivity: A Quantitative Study of Structure Sensitivity of Pd Catalysts for Acetylene Hydrogenation. Catal. Sci. Technol. 2021, 11 (15), 5212-5222.

(19) Liu, B.; Cheng, L.; Curtiss, L.; Greeley, J. Effects of van Der Waals Density Functional Corrections on Trends in Furfural Adsorption and Hydrogenation on Close-Packed Transition Metal Surfaces. Surf. Sci. 2014, 622, 51-59.

(20) Yang, B.; Burch, R.; Hardacre, C.; Headdock, G.; Hu, P. Influence of Surface Structures, Subsurface Carbon and Hydrogen, and Surface Alloying on the Activity and Selectivity of Acetylene Hydrogenation on Pd Surfaces: A Density Functional Theory Study. J. Catal. 2013, 305, 264-276.

(21) Manyar, H. G.; Yang, B.; Daly, H.; Moor, H.; McMonagle, S.; Tao, Y.; Yadav, G. D.; Hu, A. G. P.; Hardacre, C. Selective Hydrogenation of a,b-Unsaturated Aldehydes and Ketones Using Novel Manganese Oxide and Platinum Supported on Manganese Oxide Octahedral Molecular Sieves as Catalyst. ChemCatChem. 2013, 5, 506-512.

(22) Gao, Q.; Giraldo, O.; Tong, W.; Suib, S. L. Preparation of Nanometer-Sized Manganese Oxides by Intercalation of Organic Ammonium Ions in Synthetic Birnessite OL-1. Chem. Mater. 2001, $13,778-786$.

(23) Shen, Y. F.; Zerger, R. P.; DeGuzman, R. N.; Suib, S. L.; McCurdy, L.; Potter, D. I.; O’Young, C. L. Manganese Oxide Octahedral Molecular Sieves: Preparation, Characterization, and Applications. Science (80). 1993, 260 (5107), 511-515.

(24) Jakubek, T.; Hudy, C.; Gryboó, J.; Manyar, H.; Kotarba, A. Thermal Transformation of Birnessite (OL) Towards Highly Active Cryptomelane (OMS-2) Catalyst for Soot Oxidation. Catal. Lett. 2019, 149 (8), 2218-2225.

(25) Scheinost, A. C. METAL OXIDES. Encyclopedia of Soils in the Environment 2005, 428-438.

(26) Zhao, Z.; Bababrik, R.; Xue, W.; Li, Y.; Briggs, N. M.; Nguyen, D. T.; Nguyen, U.; Crossley, S. P.; Wang, S.; Wang, B.; Resasco, D. E. Solvent-Mediated Charge Separation Drives Alternative Hydrogenation Path of Furanics in Liquid Water. Nat. Catal. 2019, 2 (5), 431-436.

(27) Sun, X.; Wang, P.; Shao, Z.; Cao, X.; Hu, P. A First-Principles Microkinetic Study on the Hydrogenation of Carbon Dioxide over $\mathrm{Cu}(211)$ in the Presence of Water. Sci. China Chem. 2019, 62 (12), $1686-1697$

(28) Akpa, B. S.; D’Agostino, C.; Gladden, L. F.; Hindle, K.; Manyar, H.; McGregor, J.; Li, R.; Neurock, M.; Sinha, N.; Stitt, E. H.; Weber, D.; Zeitler, J. A.; Rooney, D. W. Solvent Effects in the Hydrogenation of 2-Butanone. J. Catal. 2012, 289, 30-41.

(29) Liu, L. M.; McAllister, B.; Ye, H. Q.; Hu, P. Identifying an O2 Supply Pathway in CO Oxidation on Au/TiO 2(110): A Density Functional Theory Study on the Intrinsic Role of Water. J. Am. Chem. Soc. 2006, 128 (12), 4017-4022. 
(30) Yadav, G. D.; Mewada, R. K. Selective Hydrogenation of Acetophenone to 1-Phenyl Ethanol over Nanofibrous Ag-OMS-2 Catalysts. Catal. Today 2012, 198 (1), 330-337.

(31) Rice, P. S.; Mao, Y.; Guo, C.; Hu, P. Interconversion of Hydrated Protons at the Interface between Liquid Water and Platinum. Phys. Chem. Chem. Phys. 2019, 21 (11), 5932-5940.

(32) Chen, L. D.; Urushihara, M.; Chan, K.; Nørskov, J. K. Electric Field Effects in Electrochemical CO2 Reduction. ACS Catal. 2016, 6 (10), 7133-7139.

(33) Cheng, T.; Xiao, H.; Goddard, W. A. Free-Energy Barriers and Reaction Mechanisms for the Electrochemical Reduction of $\mathrm{CO}$ on the $\mathrm{Cu}(100)$ Surface, Including Multiple Layers of Explicit Solvent at PH 0. J. Phys. Chem. Lett. 2015, 6 (23), 4767-4773.

(34) Herron, J. A.; Morikawa, Y.; Mavrikakis, M. Ab Initio Molecular Dynamics of Solvation Effects on Reactivity at Electrified Interfaces. Proc. Natl. Acad. Sci. U. S. A. 2016, 113 (34), E4937-E4945.

(35) Zope, B. N.; Hibbitts, D. D.; Neurock, M.; Davis, R. J. Reactivity of the Gold/Water Interface During Selective Oxidation Catalysis. Science (80-.) 2010, 330 (6000), 74-78.

(36) Blumberger, J.; Bernasconi, L.; Tavernelli, I.; Vuilleumier, R.; Sprik, M. Electronic Structure and Solvation of Copper and Silver Ions: A Theoretical Picture of a Model Aqueous Redox Reaction. J. Am. Chem. Soc. 2004, 126 (12), 3928-3938.

(37) Xu, J.; Huang, H.; Hu, P. An Approach to Calculate the Free Energy Changes of Surface Reactions Using Free Energy Decomposition on $\mathrm{Ab}$ Initio Brute-Force Molecular Dynamics Trajectories. Phys. Chem. Chem. Phys. 2020, 22, 21340-21349.

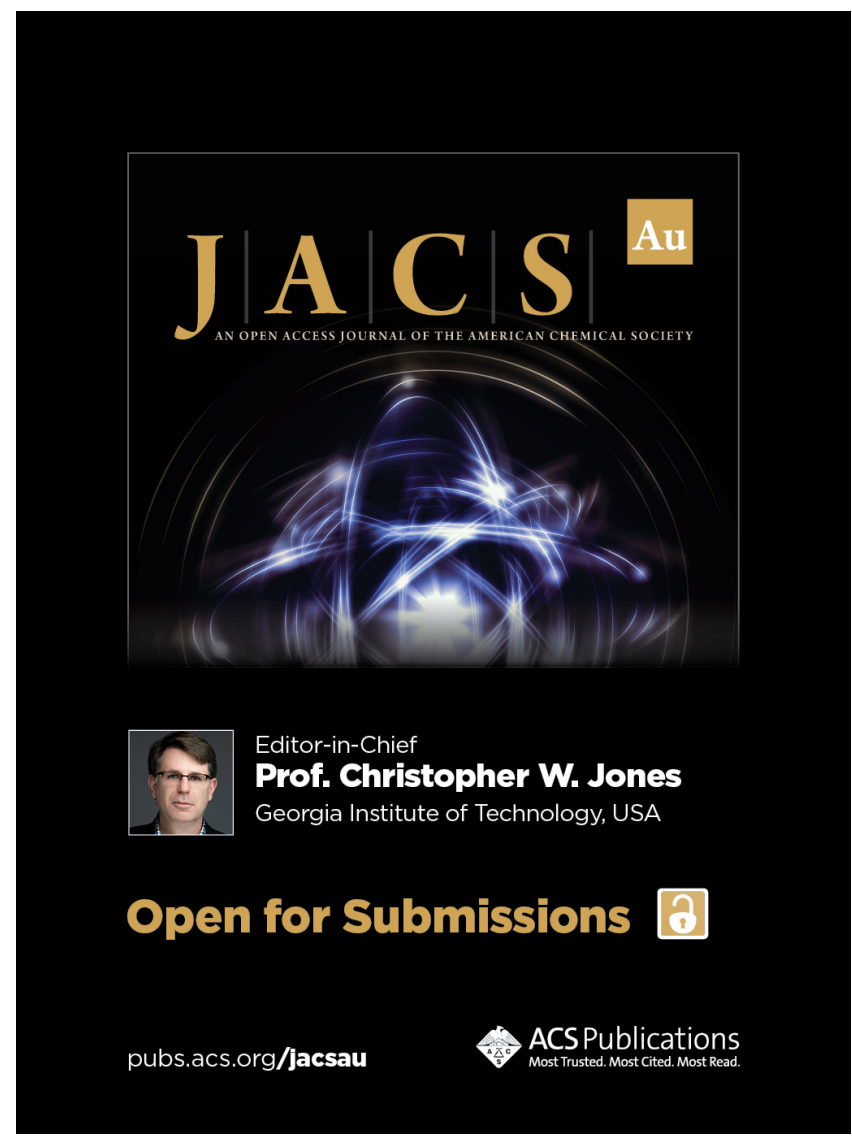

